\title{
TURISMO Y PAISAJE \\ Estrategias desde el proyecto de paisaje para el desarrollo turístico de la región costera del Gran La Plata
}

\author{
Autores: Arq. Rosario A. Román. \\ Institución: Instituto de Investigaciones y Políticas del Ambiente Construido. Facultad de Arquitectura y \\ Urbanismo, Universidad Nacional de La Plata. La Plata, Argentina. \\ EMail: roman.aylen@gmail.com.ar
}

\begin{abstract}
RESUMEN
El paisaje es un campo de estudio amplio, complejo y pluridisciplinar, de suma importancia cuando se trata de pensar en el futuro de la planificación y ordenación territorial, y en el desarrollo de espacios y destinos turísticos. El presente artículo, tiene como objetivo la formulación de estrategias de acción para la puesta en valor y apropiación de los recursos naturales y culturales de los paisajes fluviales, en pos de aportar al desarrollo productivo y turístico de la región Costera del Gran La Plata (Municipios de Berisso y Ensenada, Buenos Aires, Argentina). En una primera parte del trabajo se aborda el marco teórico en relación con el paisaje fluvial y el turismo. Posteriormente se desarrolla la fase empírica, que profundiza en la puesta en valor del paisaje en el caso de estudio. Finalmente se reflexiona acerca de las posibilidades de implementar este tipo de estrategias dentro del escenario actual.
\end{abstract}

Palabras clave: paisaje fluvial, turismo, proyecto de paisaje, región Costera del Gran La Plata.

\section{ABSTRACT}

The landscape is a broad, complex and multidisciplinary field of study, of great importance when it comes to think about the future of planning and territorial planning, and the development of spaces and tourist destinations. The objective of this article is to formulate action strategies for the valorization and appropriation of the natural and cultural resources of fluvial landscapes, in order to contribute to the productive and tourist development of the Coastal region of Gran La Plata (Municipalities of Berisso and Ensenada, Buenos Aires, Argentina). In a first part of the work, the theoretical framework is approached in relation to the fluvial landscape and tourism. Later, the empirical phase is developed, which deepens in the value of the landscape in the case of study. Finally, we reflect on the possibilities of implementing this type of strategy within the current scenario.

Key words: fluvial landscape, tourism, landscape project, Coastal region of Gran La Plata. 


\section{INTRODUCCIÓN}

El turismo es un fenómeno social de masa, que en los últimos años se ha convertido, para algunas ciudades, en un factor importante para su economía. El mismo se fundamenta gracias a la existencia y el buen estado de conservación de los atractivos turísticos (atractivos que pueden ser naturales, culturales, tangibles e intangibles), que en síntesis, son los que reflejan y dan cuenta del paisaje de dicho lugar. Es decir, que el paisaje representa uno de los principales motivos de atracción al destino. Sin embargo, en los estudios sobre turismo, el paisaje muy pocas veces es considerado como un recurso turístico. Se trata, no obstante, de uno de los recursos más delicados, frágiles y de difícil administración y recuperación (una vez degradado).

En este sentido, surge como primer interrogante de esta investigación ¿cuál es la relación estructural y conceptual entre turismo y paisaje? Si para posicionar competitivamente los destinos turísticos se considera el paisaje como un recurso, es preciso comprender ¿cuáles son los paisajes que ofrece la región costera del Gran La Plata? es decir, ¿cuáles son los aspectos físicos, ecológicos, y culturales que fue adquiriendo la región en los procesos que determinaron su ocupación, que la diferencian y otorgan identidad? Y ¿cuáles de estos aspectos pueden ser considerados hoy en día como posibles recursos y activos turísticos? ¿Qué estrategias, desde el proyecto de paisaje, pueden ser puestas en práctica para contribuir a la puesta en valor, apropiación e integración de esos recursos?

Ante estos interrogantes, surge la siguiente hipótesis: La percepción del paisaje como objeto de consumo visual del territorio, evidencia su valor de cambio a manera de un recurso activo para el desarrollo de la actividad turística. Teniendo en cuenta esto, el paisaje es concebido como una herramienta clave para el desarrollo de alternativas en los procesos de planificación y gestión turística.

En este contexto, el trabajo tiene por finalidad presentar la síntesis y conclusiones del Taller de Proyectos de la VI cohorte de la Maestría "Paisaje, Medio Ambiente y Ciudad" de la Facultad de Arquitectura y Urbanismo de la Universidad Nacional de La Plata (Acreditación CONEAU Categoría B Resolución 1316/12. Director: Mgr. Arq. Leandro Varela; Director Consulto: Arq. Olga Ravella; Co-Director: Dr. Arq. Gustavo San Juan). En este sentido, se presenta un trabajo que en primer lugar asume un posicionamiento en relación a la compleja y múltiple conceptualización, e indisociable relación entre el turismo y el paisaje, ya que toda experiencia turística implica un acto de percepción predominantemente visual del paisaje visitado, convirtiéndolo en un elemento substancial del fenómeno turístico y en un recurso de gran valor para el desarrollo y la consolidación de la oferta turística. En segundo lugar asume una mirada: el agua es inmanente al área de estudio y por tanto argumento de proyecto; finalmente, asume un área de proyecto: las islas (Santiago y Paulino, correspondientes a los Municipios de Berisso y Ensenada), que permiten abordar la complejidad del territorio, sus desafíos y oportunidades, así como recuperar las potencialidades del paisaje ribereño.

De acuerdo a lo expuesto, el trabajo tiene como objetivo general la formulación de lineamientos y estrategias de acción para la puesta en valor y apropiación de los recursos naturales y culturales de los paisajes fluviales, en pos de aportar al desarrollo productivo y turístico de la región.

Como objetivos específicos, se proponen: 1 . Aportar al desarrollo turístico de la región a través de la revalorización del paisaje ribereño, integrando no solo elementos sino también procesos y estrategias, tanto espaciales como temporales. 2. Fortalecer las potencialidades reconocidas en el diagnóstico con la finalidad de generar una relación novedosa entre la producción local viñatera y el turismo asociado a esta actividad. 3. Generar lineamientos que protejan el paisaje ribereño y todas aquellas áreas de intervención que pueden ser afectadas por la expansión urbana y demás actividades del hombre. 4. Involucrar a la comunidad en la gestión del territorio, para lograr la apropiación del proyecto por parte de los habitantes a través de la participación ciudadana.

\section{PAISAJE, TURISMO Y PROYECTO DE PAISAJE}




\subsection{El concepto de Paisaje.}

La Convención Europea del Paisaje (2000) define al Paisaje como "Cualquier parte del territorio, tal y como es percibida por las poblaciones, cuyo carácter resulta de la acción de los factores naturales y humanos y de sus interrelaciones". Es decir, la definición, hace referencia, por un lado, al hecho objetivo que todo territorio es paisaje "cualquier parte del territorio", por otro, a su aspecto subjetivo o social "tal como es percibido por las poblaciones» y una tercera y final consideración a su base causal «resultado de la interacción de factores naturales y humanos", reflejando la idea de que los paisajes evolucionan a lo largo del tiempo, como resultado de la actuación de las fuerzas naturales y humanas y destacando que un paisaje forma un todo, cuyos componentes naturales y culturales se toman de forma conjunta, y no de forma separada.

Milton Santos (2000) afirma al hablar de paisaje que es "El conjunto de formas que, en un momento dado, expresa las herencias que representan las sucesivas relaciones localizadas entre el hombre y la naturaleza. (...)El paisaje existe a través de sus formas, creadas en momentos históricos diferentes, aunque coexistiendo en el momento actual (...) una especie de palimpsesto donde, mediante acumulaciones y sustituciones, la acción de diferentes generaciones se superpone".

El paisaje debe ser entendido como un todo, como una composición compleja, en la que se encuentran en constante interacción los objetos, los sujetos y el entorno; al tratar de comprender estos elementos por separado se tiende a una ruptura del paisaje, de su identidad, y de su significado. La construcción colectiva del paisaje, no solo se da por la actual interacción de objetos, sujetos y entorno, sino también por la historia de cada uno de los elementos, por la huella que van dejando en el territorio.

Marc Besse (2006) postula que "Se ha tomado conciencia de que el suelo posee un espesor, un espesor que no solo es material sino también simbólico. Lo que significa que el suelo es el efecto de una construcción histórica, que es el portador de toda una superposición de pasados y que, al mismo tiempo, es una reserva de energías futuras. En otros términos, recurrir al paisaje refleja la toma de conciencia de que el espacio no es una página en blanco, sino más bien un palimpsesto. El suelo no es una superficie plana que se ofrece para la acción, sino que confronta la acción con un conjunto más o menos denso de trazos, de huellas, de plegados y de resistencias a los que debe acomodarse la acción..."

Bajo esta aproximación, se entiende al paisaje como el resultado de la interacción entre el hombre y la naturaleza. Es decir, el paisaje es la cultura territorial de una sociedad determinada. Este planteamiento tiene dos significados principales. El primero, es el reconocimiento de que el territorio contiene y expresa a través de la noción de paisaje, las formas de actuar del grupo humano que lo ocupa y lo maneja con distintos fines (de subsistencia, productivos, simbólicos). Y por otra parte, reconoce que existen valores colectivos en las formas y en la organización del espacio vivido y que estos se asocian a la identidad o a la cultura propia.

El paisaje es concebido como el aspecto visible y perceptible de un determinado espacio. Como se observa en todas las definiciones anteriormente citadas, el concepto de paisaje implica la existencia de un observador, de alguien que contempla y analiza esta porción del espacio desde un punto de vista determinado. El observador, en este caso será el turista. El paisaje es, por lo tanto, un concepto impregnado de connotaciones culturales, e incluso ideológicas. "El paisaje no es sólo el mundo tal cual, sino que también es, una construcción, una composición de este mundo. El paisaje es una forma de ver el mundo" (Font J. N. 1989)

\subsection{El concepto de Turismo.}

La relación entre los conceptos de paisaje y turismo se da, en primer lugar, a partir de la comprobación de que la motivación fundamental para el viaje turístico es la necesidad de romper con la rutina. Según Font (1989), para muchos, la forma de conseguir esta ruptura, es a través del cambio físico de lugar, actitud que forma parte de la esencia del turismo. Es en el paisaje, en donde el turista encontrará el elemento que 
indicará la ruptura con la percepción visual de lo nuevo y lo diferente en el transcurso de la experiencia del viaje.

"El turismo debe ser concebido como el complejo conjunto de relaciones y fenómenos que se desprenden de los desplazamientos y de las estancias temporales, en un lugar determinado, por parte de gente que procede de otro lugar, y que viaja por motivos recreacionales o de placer... La razón de ser del turismo, aquello que más caracteriza al fenómeno turístico es, sencillamente, el voluntario desplazamiento movimiento- de la gente de un lugar a otro en el espacio" (Font J. N. 1989).

Según Font (1989), el turismo se trata de una "experiencia geográfica", es decir, el viaje turístico consiste en la búsqueda de la sustitución de los paisajes cotidianos, cargados de símbolos culturales que recuerdan la pertenencia a una determinada comunidad, por aquellos otros paisajes, en que las costumbres, clima, vegetación, color y luz, son probablemente diferentes. Es decir, se busca traspasar el límite del espacio conocido, por el desconocido. La "experiencia geográfica" como la denomina Font, se asienta sobre dos pilares: el lugar de origen y el punto de destino. Ambos focos están conectados física y psicológicamente por un tercer elemento, el viaje. El paisaje es la representación de las costumbres y de los valores culturales de una comunidad. Por lo tanto, el paisaje debería ser para el turista una ventana abierta hacia una nueva cultura.

En este sentido, el paisaje resulta un elemento esencial del fenómeno turístico y un recurso de gran valor para el desarrollo y la consolidación de la oferta turística. Todo ello si es que previamente, el territorio no ha sido desestructurado por una excesiva e inadecuada acción antrópica. Ya que paradójicamente, siendo como es el paisaje un valor fundamental en toda oferta turística, nos encontramos con que el turismo es hoy uno de los causantes más importantes de su degradación.

\subsection{El proyecto de paisaje como recurso para el turismo.}

Etimológicamente la palabra proyecto proviene de projectum, projectus y adquiere varios significados como: una pieza de investigación definidamente formulada. Idear en la mente. Lanzar hacia adelante. Planear, prefigurar o estimar el futuro. Esquema subyacente que gobierna funcionamientos desarrollos o despliegues. Muchas veces, la escasa preparación para comprender y trabajar con el medio natural por parte de arquitectos, diseñadores y profesionales de perfil más científico conduce al deterioro de los sistemas naturales de la tierra. La situación actual ha derivado en una variedad de reacciones por parte de los proyectistas y como consecuencia, hay numerosos puntos de vista acerca de qué es un proyecto ecológicamente responsable. Como mencionamos anteriormente, se entiende al paisaje como el efecto de la superposición de la actividad humana sobre la naturaleza, e incluye las modificaciones derivadas de la actuación sobre el medio para hacerlo productivo - parcelaciones, áreas cultivadas, minería, forestación y deforestación, dehesas, pastos y ganaderías, etc.- y construir artificialmente sobre él, sean infraestructuras -puentes presas caminos, etc.- o realizaciones propiamente arquitectónicas. Se trata, por tanto, de un término que implica una orientación proyectual clara y una condición híbrida, natural y artificial: la proyección de la cultura- tanto en su significado etimológico como el convencional- sobre el territorio natural. (ABALOS, 2005).

A partir de aquí, se sostiene que el paisaje no es solo objeto de conservación sino que puede ser también sujeto de proyecto. Por lo tanto, se entiende al paisaje como una forma de - mirar y el proyecto de paisaje como una forma de -activar el territorio. (BAPTISTA, 2013)

"Un proyecto de Paisaje por su propia esencia no acaba en la documentación técnica, sino que necesariamente debe incluir los lineamientos de su gestión y su evolución temporal. Es por tal motivo que el mismo no define únicamente formas preestablecidas, sino en primera instancia define criterios de valorización, los cuales van evolucionando en formas cambiantes a través del tiempo" (Santinelli 2015). Este concepto aporta a nuestro trabajo los criterios de gestión y valorización, los cuales creemos fundamentales en la relación paisaje, desarrollo local y turismo. En primer lugar, la gestión o la manera de 
llevar a cabo el proyecto implica un análisis de los actores sociales que son partícipes de esa relación hombre-entorno de la cual resulta el paisaje. En segundo lugar, los criterios de valorización abarcan un importante abanico desde los aspectos históricos, culturales, simbólicos ecológicos y sociales.

A partir de estas definiciones, es necesario reflexionar sobre la necesaria relación armónica entre el desarrollo turístico, el ambiente y el paisaje. El proyecto de paisaje debería tener en cuenta la sostenibilidad de sus recursos naturales y culturales, y por consiguiente la búsqueda de su valoración. Entender el paisaje como recurso turístico implica considerar procesos de manejo como medio para su conservación y creación. Y al hablar de conservación, nos referimos a conservar la autenticidad de un paisaje. No se trata de mantenerlo intacto, fosilizarlo. Todo lo contrario. El paisaje como se comentó anteriormente, es el resultado de una tensión dialéctica continua entre elementos abióticos, bióticos y antrópicos, por lo tanto es dinámico. El proyecto de paisaje debiera intentar conservar la especificidad y originalidad de sus elementos constituyentes sin cuestionar su dinamismo. Sólo así se puede hablar del paisaje como un recurso turístico.

\section{CASO DE ESTUDIO: REGIÓN COSTERA DEL GRAN LA PLATA.}

El área de trabajo se sitúa en la franja costera del Río de la Plata comprendiendo los Municipios de Berisso y Ensenada de la provincia de Buenos Aires, Argentina.

Este es un área característica que forma parte del Área Metropolitana de Buenos Aires (AMBA), la cual cuenta con uno de los porcentajes poblacionales más elevados de Argentina, así mismo un alto porcentaje de déficits, lo que sin lugar a dudas afecta al área de trabajo. Sin embargo, al ser un sector de borde costero cuenta con características paisajísticas singulares, que están dadas no solo por su situación geográfica, sino también por las dinámicas sociales propias del lugar.

En este contexto, el sector elegido posee dos características, una, la de pertenecer a un sector particular del Gran Buenos Aires en el marco de la dinámica propia de la periferia urbana, ligada al centro capitalino y a la tensión provocada por la vinculación con la ciudad de La Plata, la otra, la de considerarse como un área costera. La tensión a partir de las vías de vinculación y de dependencia mutua, provocada entre CABA y el Gran La Plata (La Plata, Berisso y Ensenada) y sus extensiones urbanas ubicadas en forma aledaña al río, ofrece un interesante margen de investigación y producción de hábitat.
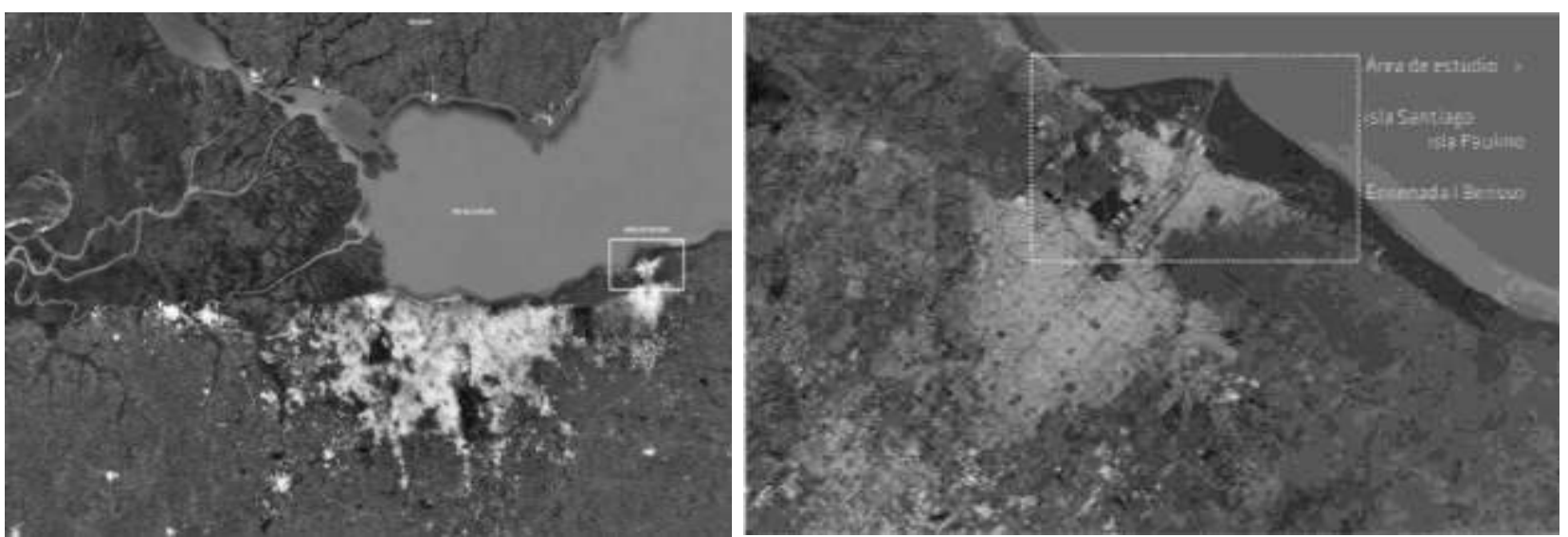

Área metropolitana del Gran Buenos Aires y Región Gran La Plata.

Elaboración propia en base a imagen tomada de google earth.

\section{ABORDAJE METODOLÓGICO.}

El planteo metodológico que se realiza en el presente trabajo consiste en la adopción de tres instancias diferenciadas en el proceso de la información: 1) Una primera instancia de Diagnóstico general de las 
ciudades costeras de Berisso y Ensenada, la cual permitió conocer la Región Costera y las problemáticas más relevantes en ella, en pos de ajustar el recorte del área y el tema de intervención, 2) seguida de una síntesis y análisis propositivo, la cual posibilito el reconocimiento de las cuestiones que serían necesarias transformar y las que se deberían potenciar, y así establecer líneas estratégicas de acción, para concluir finalmente, 3) se procede a desarrollar en una tercera instancia estrategias para intervenir el territorio desde la mirada del paisaje. Todas las instancias nutren de información y resultados a la siguiente fase de trabajo, avanzando en la definición del proyecto y en el proceso de la información de la siguiente manera:

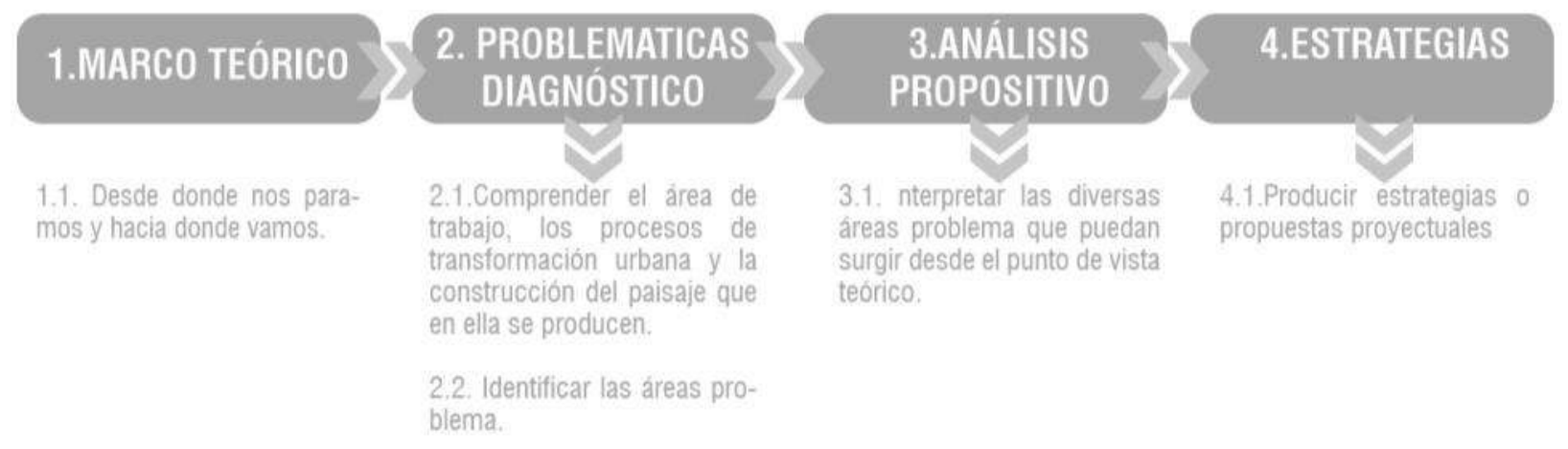

Esquema de la metodología empleada.

Elaboración propia.

\subsection{CARACTERIZACIÓN Y DIAGNÓSTICO.}

El diagnóstico busca aportar al entendimiento del territorio como un constructo social complejo, que al mismo tiempo es objeto configurado y objeto de representación, apropiación, organización, construcción, reproducción y transformación. Conocer y comprender su proceso y dinámica requiere un acercamiento a su multidimensionalidad, que articula lo natural, lo social, lo económico, lo político y lo cultural desde donde el ser humano, la colectividad, construye el territorio. Partiendo de esta visión compleja, se reconoce la interrelación entre las dimensiones que componen el objeto y se adopta como metodología, la basada en la superposición de varias capas de proyecto y regulación interdependientes, es decir, una estructura de interpretación y proyecto multicapas ${ }^{1}$. Estas capas o layers contemplan los siguientes tres enfoques: 1. "ecológico-ambiental", 2. "histórico-social", y 3. "urbano-territorial".

1. El enfoque "ecológico - ambiental" se orienta a la comprensión de la estructura y dinámicas del territorio. Con respecto a los factores climáticos, corresponde mencionar el fenómeno de la "sudestada", la cual consiste en fuertes vientos del sureste, acompañados por lluvias persistentes débiles o moderadas. Estos vientos producen una elevación del nivel de las aguas del Rio de La Plata, originando inundaciones en la zona ribereña. En cuanto a la forma del territorio, se tiene, hasta el límite del partido de La Plata aproximadamente, la alta terraza con cotas mayores a 5 msnm y suaves ondulaciones. A partir de allí, se da un pronunciado escalón hacia la baja terraza que tiene como característica el que las aguas procedentes de la zona alta no llegan al Río de la Plata, acumulándose en el bañado Maldonado. Por otra parte, existe una rica diversidad biológica, destacándose los relictos de selvas ribereñas. En suelos más o menos altos se desarrolla el Talar del bosque, generalmente sobre albardones de conchilla. En cuanto a la fauna, destaca la concentración de aproximadamente 300 especies de aves.

2. El enfoque "histórico - social" incluye el análisis del paisaje focalizándose desde su dimensión visual, entendido de que la visualización del paisaje es el primer paso para la visibilización de los procesos subyacentes. En este enfoque también se incluye la caracterización patrimonial. Para ello se recurre a la noción de patrimonio en sentido amplio, apostando por el reconocimiento de aspectos de distinta naturaleza que podrían constituirse en activo a pontenciar para el desarrollo

\footnotetext{
${ }^{1}$ Joaquim Sabaté, Proyectar el territorio en tiempos de incertidumbre.
} 
de la comunidad. Como señala Mata Olmo (2010.42), "la valorización de los recursos patrimoniales adecuadamente gestionada, constituye, en contextos muy diversos, un estímulo para el desarrollo local". En particular, se consideran de interés las prácticas materiales de los isleños, tanto en lo que lo que hace a la producción vitivinícola adaptada al régimen indundación, mediante un sistema de plantación en parral asociado a una intrincada red de zanjas y canales, como al recurso de la construcción palafítica. A esto se suma: las zonas de riqueza ambiental; los principales elementos estructurantes de la matriz antrópica del territorio; elementos de carácter objetual -arquitectónicos, industriales, infraestructurales-; conjuntos urbanos y, finalmente, el patrimonio inmaterial.

3. El análisis del enfoque "urbano-territorial" implica el estudio de los usos del suelo, la puesta en relación de la legislación vigente -en particular las leyes provinciales 8912 de usos del suelo y 12756, la cual declara "Paisaje Protegido de Interés Provincial" para el desarrollo ecoturístico a la zona que se denomina "Monte Ribereño Isla Paulino, Isla Santiago"-con la idoneidad de usos de los suelos y usos actuales. Por otra parte, la dimensión infraestructura y conectividad se centra en las grandes infraestructuras y su accesibilidad, así como en la cobertura de servicios.
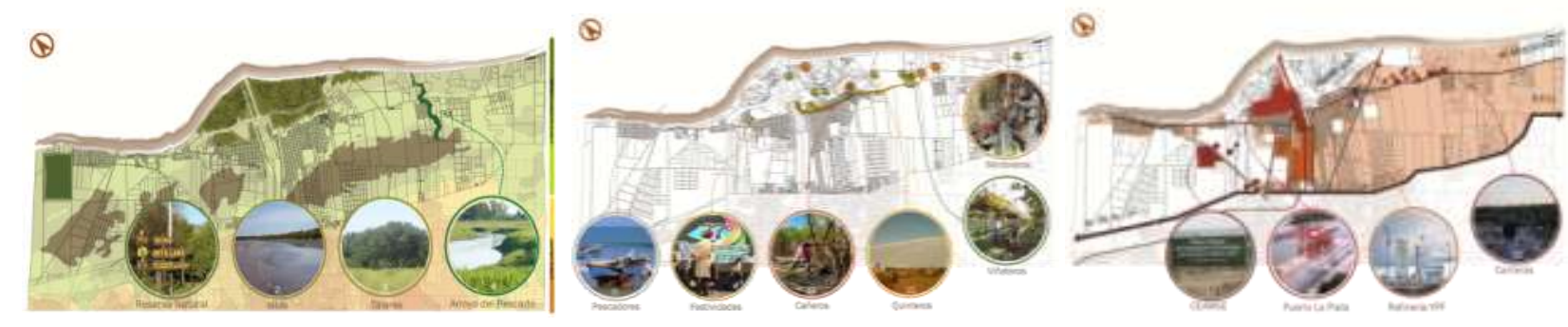

Síntesis del diagnóstico: Enfoque "ecológico-ambiental"; enfoque "histórico-social"; enfoque "urbano-territorial". Elaboración propia.

\subsection{ANALISIS PROPOSITIVO}

El diagnóstico permitió realizar una evaluación de los recursos naturales y culturales y su acción inmediata sobre el paisaje, y el reconocimiento de los escenarios actuales en el que se manifiestan las distintas realidades, dinámicas y relaciones que atraviesan el territorio. En este sentido, permitió reconocer las potencialidades y debilidades, como cuestiones tangibles e intangibles que posteriormente serán retomadas para proponer e intervenir.

Para el desarrollo de esta instancia, se apuesta a la caracterización de unidades de paisaje (UP), la cual permitió la identificación, a modo de hipótesis, de características que permitan hablar de paisajes con una cierta condición de unicidad. Esta identificación tiene como objetivos, por un lado, coadyuvar a la detección de los patrones de ocupación del territorio -y el paisaje resultante como producto material- y, por otro, la construcción de argumentos para el desarrollo local del área apoyado en el turismo. Como resultado, se logró la caracterización e identificación de las siguientes UP, diferenciadas en 3 escalas de abordaje: escala Macro, escala Meso, y finalmente la escala Micro, a partir de la cual se desarrollarán lineamientos y estrategias tanto de gestión como proyectuales. 


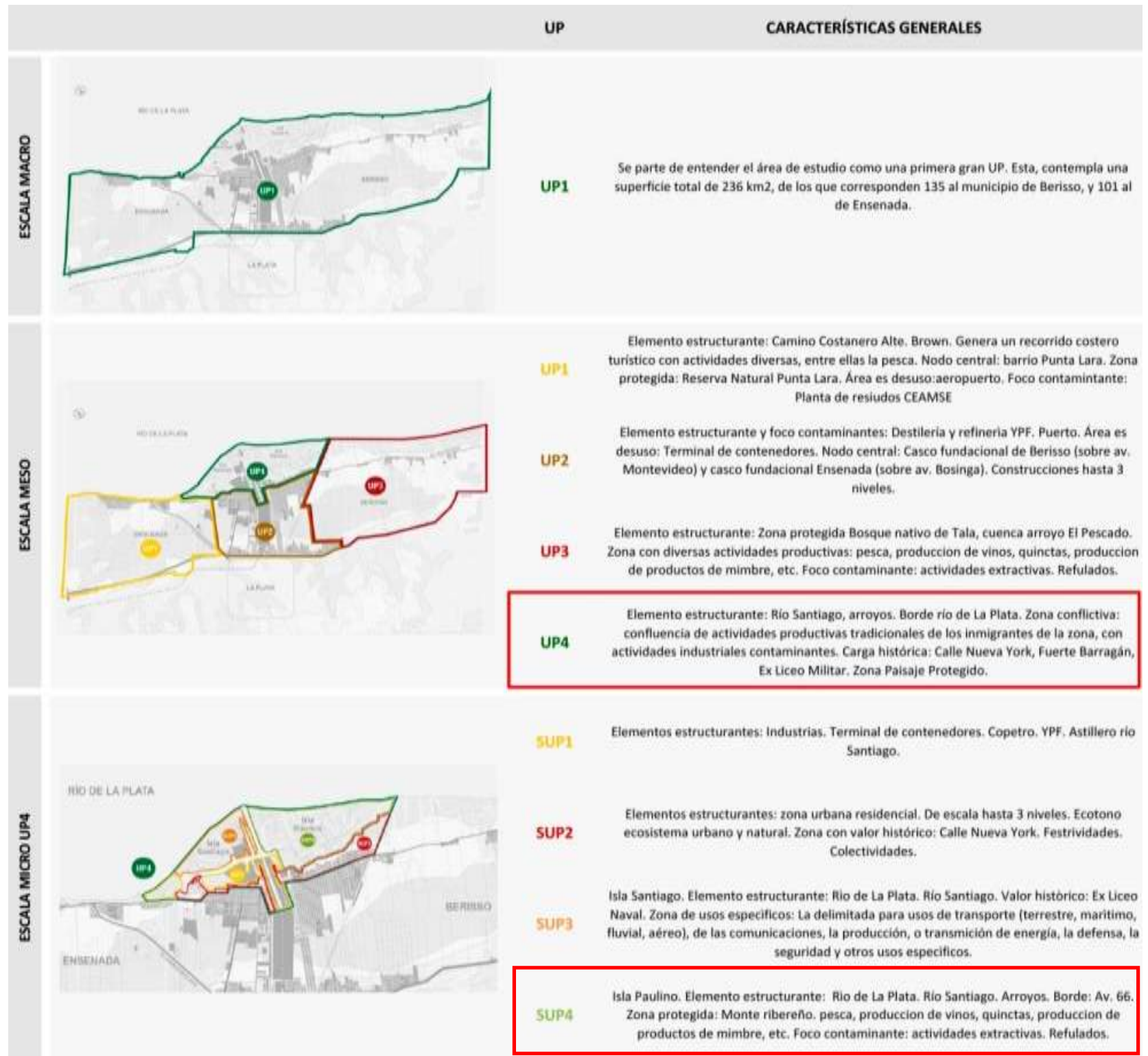

Unidades de Paisajes detectadas.

Elaboración propia.

\subsection{PRIMERA ESCALA DE ABORDAJE: UP4.}

Como área de proyecto se toma la UP4: Islas Santiago y Paulino, territorio dónde se manifiestan los principales conflictos socio-ambientales y regulatorios identificados, así como las mayores potencialidades, y cuyos límites son: el Río de La Plata, el Río Santiago, el canal que bordea la terminal de contenedores, la defensa costera y la Avenida 66.

\section{Caracterización de la UP4: Delta del Río Santiago y sus Islas: Santiago y Paulino.}

El Delta del Río Santiago es un pequeño sistema deltaico que se conforma, adyacente al Río de la Plata, por el Río Santiago de 8 kilómetros de longitud y los aportes de los arroyos El Gato, Zanjón y el Canal Oeste que confluyen en este último. La Planicie costera que constituye el Delta del Río Santiago es un paisaje singular donde actualmente se desarrollaron dos centralidades urbanas, Berisso y Ensenada, separadas por el Puerto de La Plata. Esta planicie forma parte de la región de humedales identificada como "Cuenca del Plata" y "Sistema del Río de la Plata" (Canevari. 1998), cuya singularidad se funda tanto en su génesis como en su transformación a través del tiempo. 
En 1883, cuando se comenzó a construir el Puerto de La Plata, la isla Río Santiago (cuyo nombre fue impuesto en el siglo XVI por el colonizador Juan de Garay) quedó dividida por un canal de acceso a dicho puerto en dos porciones insulares, la Isla Santiago Oeste hoy en día llamada "Isla Santiago", que pertenece al partido de Ensenada, y la Isla Santiago Este hoy en día llamada "Isla Paulino", que pertenece al partido de Berisso (Michellod, 2001).

Los primeros habitantes de la Isla Santiago fueron obreros, en su mayoría de origen italiano, español y uruguayo, que participaron en la construcción del Puerto y en el dragado de canales de acceso alternativos (Michellod, 2001). Actualmente, la Isla es habitada, según INDEC 2011, por 193 personas, cuyas viviendas son típicamente de chapa y madera, construidas elevadas por las frecuentes inundaciones en el lugar, conectadas por estrechos pasadizos rodeados de vegetación. La Isla Paulino, en cambio, es habitada actualmente por aproximadamente 50 personas que viven en su mayoría en casas distribuidas a orillas del canal de acceso al Puerto. Las personas que habitan de modo permanente en las Islas viven de la crianza de animales (cerdos, gallinas), del trabajo producido con mimbre, de la pesca, y de sus propias quintas, donde cultivan frutales (uva chinche, ciruelas, cítricos, tomate, ajíes, zapallos, etc.) y hortalizas (acelga, repollito de Brusellas, etc.). Es importante destacar que particularmente, en la isla Paulino, se produce un vino de uva chinche conocido localmente como el "vino de la costa" para consumo personal, compradores ocasionales (turistas) y para la venta en los comercios de la ciudad de Berisso.

La confluencia de quinteros, viñateros, cañeros, el puerto y las actividades industriales priman en esta unidad. Su carga histórica, simbólica y cultural es importante, debido a que en esta unidad se encuentra la Calle Nueva York, el Fuerte Barragán, el Ex Liceo Militar y un gran número de festividades enriquecidas por la cantidad de colectividades situadas en el sector; además de contar con una zona importante de paisaje protegido, el Monte Ribereño.

A su vez, surge en esta etapa la mirada que desencadena luego el desarrollo de proyecto: el agua ha sido una de las principales materias con las que se han ido modelando los paisajes del área, destacándose, entre otros aspectos, las prácticas agrícolas asociadas al régimen de inundación. Si bien el agua puede entenderse como un emergente de las amenazas del presente, su adecuado manejo se observa, por otra parte, como una oportunidad para la conservación y el desarrollo del área.

Las islas, como idea, remite a lo que se escinde del todo, a lo que tiene cierta condición de unicidad, al tiempo que lleva a la necesidad de reflexionar acerca de sus conexiones. Si alguna vez las islas Santiago y Paulino fueron el sitio de recreo de los habitantes de la zona, hoy parecen condenadas al ostracismo, al tiempo que representan la tenacidad de sus pobladores para la construcción de un paisaje habitable. Las islas recuperan la unidad del territorio previa a la construcción del puerto, pero reconoce el nuevo borde generado con la construcción de defensa costera.

\section{Cuadro síntesis de recursos naturales y culturales UP4:}

Se procede a catalogar los elementos constitutivos de la UP4, es decir, sus recursos naturales y culturales. Se realiza un proceso documental de las manifestaciones naturales y culturales, internalizando la importancia histórica, arquitectónica, ecológica y de sentir comunitario, como factor de desarrollo turístico. Para ello se, se identifican y catalogan los recursos a partir de tres criterios:

- Para los recursos naturales. Diversidad, singularidad, representatividad, probabilidad de observación, valores turísticos, grados de contaminación

- Para los recursos culturales. Valores de autenticidad, valores colectivos, asociativos y testimoniales, populares, de tradición, de antigüedad, arquitectónicos, de conservación, históricos, urbanos, tecnológicos, de funcionalidad, de identidad, de representatividad. Eventos y festividades: Institucionalidad y organización, beneficios socio-económicos, beneficios para el desarrollo, beneficios económicos locales, valores de singularidad. 


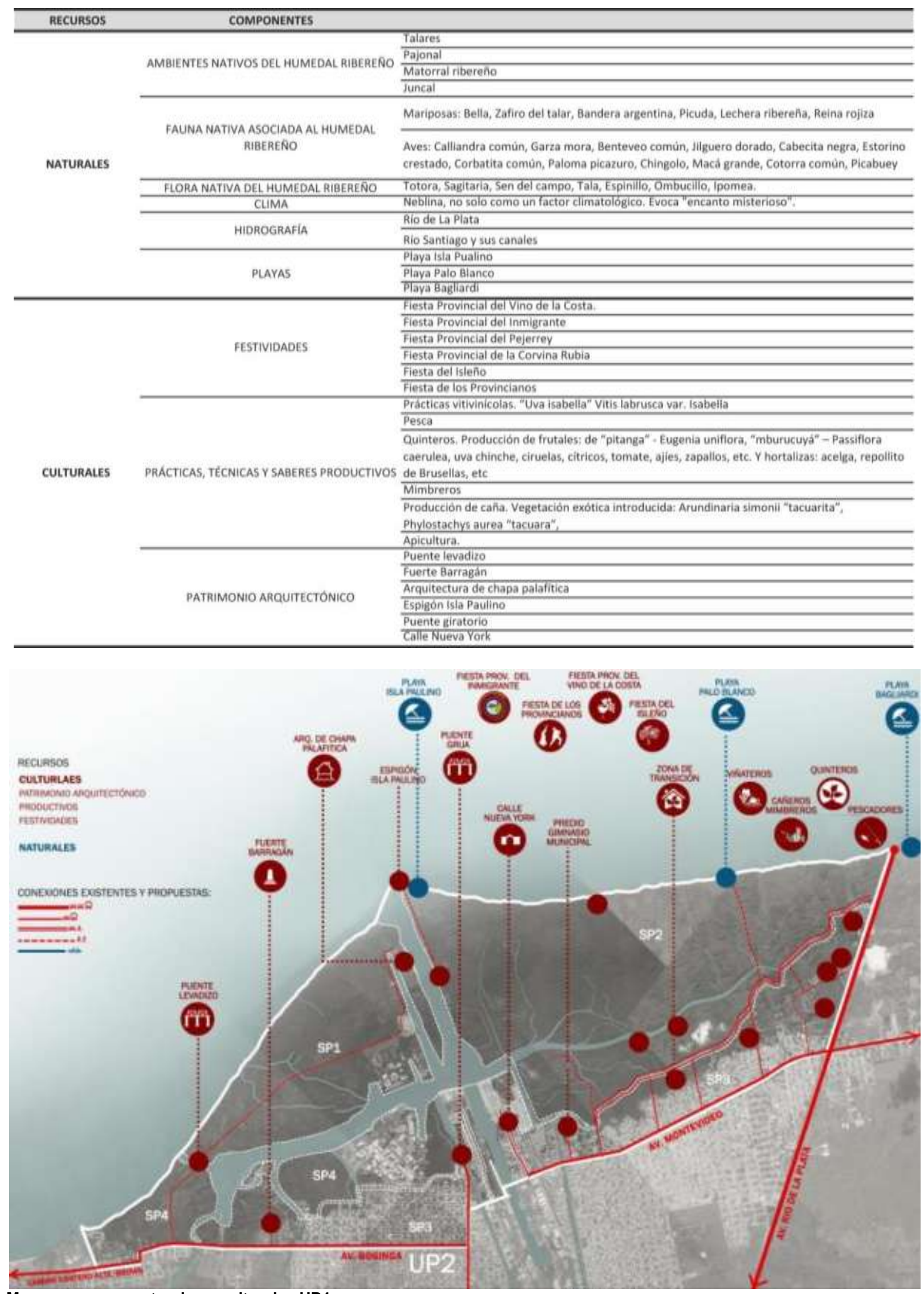

Mapeo recursos naturales y culturales UP4.

Elaboración propia. 


\section{Estrategias de gestión para el desarrollo productivo y turístico:}

En esta escala, se establecieron líneas y estrategias de gestión que apunten a orientar políticas públicas a fin de expandir la intervención a toda el área de estudio. Para ello se trabaja en base a tres ejes principales que permitirán organizar y priorizar las distintas estrategias a partir de su organización temática. Estos tres ejes, descriptos a continuación, se entrecruzan con tres planos de acción identificados durante el análisis, lo que permitirá lograr un abordaje transversal de la problemática.

Eje 1 Ambiental: Establecer acciones que tiendan a lograr un medioambiente sano, apto para el desarrollo armónico e integral de todas las actividades humanas.

Eje 2 Turismo y producción local: Reconfigurar las actividades relacionadas al turismo y la producción local de Berisso y Ensenada en pos de apuntar al desarrollo turístico de la región.

Eje 3 Urbano: Remediar los efectos de una ocupación del territorio sin planificación, apuntando a recomponer la relación fragmentada entre el tejido urbano y la costa del rio.

\begin{tabular}{|c|c|c|c|}
\hline \multirow{2}{*}{ EJES ESTRATÉGICOS } & \multicolumn{3}{|c|}{ PLANOS DE ACCIÓN } \\
\hline & CULTURAL & TRANSPORTE E INFRAESTRUCTURA & INSTITUCIONAL \\
\hline \multirow{4}{*}{ AMBIENTAL } & $\begin{array}{l}\text { Concientizar a la población sobre la fragilidad } \\
\text { e importancia del medioambiente a través de } \\
\text { acciones como la Educación Ambiental, para } \\
\text { impulsar una relación responsable y amigable } \\
\text { con el ambiente. }\end{array}$ & $\begin{array}{l}\text { Diseño de infraestructura y mobiliario } \\
\text { necesario que no entorpezcan el equilibrio } \\
\text { ecosistémico. }\end{array}$ & $\begin{array}{l}\text { Brindar cursos gratuitos que orienten en la } \\
\text { protección y conservación del patrimonio } \\
\text { vegetal. }\end{array}$ \\
\hline & Gestión y recuperación del agua. & $\begin{array}{l}\text { Restauración de suelos mediante la plantación } \\
\text { de vegetación nativa que absorba metales } \\
\text { pesados. }\end{array}$ & Gestión y recuperación del agua. \\
\hline & $\begin{array}{l}\text { Remediación, saneamiento y recuperación de } \\
\text { las playas. }\end{array}$ & $\begin{array}{l}\text { Controlar la llegada de turistas dentro de la } \\
\text { zona protegida }\end{array}$ & Protección y fomento de la biodiversidad. \\
\hline & & Estacionamientos perimetrales. & Promoción de la utilización de flora nativa \\
\hline \multirow{5}{*}{$\begin{array}{c}\text { TURISMOY Y } \\
\text { PRODUCCIÓN LOCAL. }\end{array}$} & $\begin{array}{l}\text { Construir nuevos espacios para la inclusión de } \\
\text { nuevos emprendedores y productores locales. }\end{array}$ & $\begin{array}{l}\text { Diseño de corredores de vinculación entre la } \\
\text { ciudad y el rio. }\end{array}$ & $\begin{array}{l}\text { Puesta en valor del patrimonio arquitectónico } \\
\text { como bien cultural y agente promotor del } \\
\text { turismo. }\end{array}$ \\
\hline & & $\begin{array}{l}\text { Establecer nodos de actividades } \\
\text { interconectados. }\end{array}$ & $\begin{array}{l}\text { Incorporar la Fiesta del Inmigrante, la Fiesta } \\
\text { del Vino de la costa a una guía de promoción } \\
\text { turística y vincularlos con los nuevos espacios } \\
\text { propuestos. }\end{array}$ \\
\hline & & $\begin{array}{l}\text { Recorridos restringidos para asegurar la } \\
\text { conservación de la biodiversidad }\end{array}$ & \\
\hline & & Diseño de riberas y márgenes del rio. & \\
\hline & & $\begin{array}{l}\text { Incorporación de equipamiento para } \\
\text { visitantes en quintas; fomento de campings; } \\
\text { construcción palafítica. }\end{array}$ & \\
\hline \multirow[t]{2}{*}{ URBANO } & $\begin{array}{l}\text { Formular diseños adecuados que favorezcan } \\
\text { la apropiación de espacios públicos para } \\
\text { fortalecer el sentido de pertenencia. }\end{array}$ & Articular espacios libres y movilidad. & $\begin{array}{l}\text { Gestión de nuevos parcelamientos enfocados } \\
\text { a usos públicos. }\end{array}$ \\
\hline & $\begin{array}{l}\text { Fomentar el uso de flora nativa, sobre todo en } \\
\text { el arbolado urbano. }\end{array}$ & $\begin{array}{l}\text { Contener la expansión del área urbana sobre } \\
\text { el monte. }\end{array}$ & \\
\hline
\end{tabular}

\subsection{SEGUNDA ESCALA DE ABORDAJE. SUP4.}

En esta instancia, se propone desarrollar estrategias no solo desde la gestión, sino también intervenciones proyectuales sobre el territorio. Para ello, se decide bajar de escala, y trabajar sobre la SUP4.

Esta ubicación permite potenciar el "corredor ecológico" desde la Reserva de Biosfera Pereyra Iraola, hasta la cuenca del arroyo el Pescado, declarada Paisaje Protegido (Ley 12.247). Hoy en día, este corredor se encuentra interrumpido en distintos sectores, por intervenciones antrópicas (avance de la 
urbanización, actividades mineras, desechos industriales depositados en las islas, etc.) que producen daños ambientales irreversibles, y pérdidas de cientos de hectáreas de monte ribereño.

El área seleccionada limita con el Terraplén Costero y la Av. Río de La Plata. Esta ubicación es estratégica para el proyecto ya que asegura una accesibilidad eficiente, desde los Municipios de Berisso, Ensenada y La Plata. A su vez, el área integra el sendero de los viñedos conocido como "Camino del Borracho", el cual permite conocer las distintas actividades que desarrollan los productores de la zona.

El área también integra una de los cuatro Reservorios realizados como parte de la obra del Terraplén Costero. Dicha estación de bombeo y reservorio cumplen la doble función de evitar el paso de agua ante las crecidas del Río de La Plata y a su vez reservar y expulsar el agua que llega por cauce natural desde la ciudad de La Plata y distintos barrios de Berisso. Esta obra realizada, con una mirada sesgada de la problemática de las inundaciones, puso su foco de atención exclusivamente en los aspectos técnicos de las obras hidráulicas, dejando de lado las cuestiones de diseño, movilidad urbana, calidad del espacio urbano (particularmente de sus espacios verdes) y calidad de vida de la población e incluso de la falta de espacios verdes en la ciudad.

A su vez, el sector seleccionado incorpora al proyecto a la escuela Nro. 15 de Berisso y a la escuela Agropecuaria Nro. 1 "Tierra de inmigrantes". Se propone un trabajo de intercambio entre ambas instituciones, fundamental para impulsar el desarrollo territorial sostenible del área.

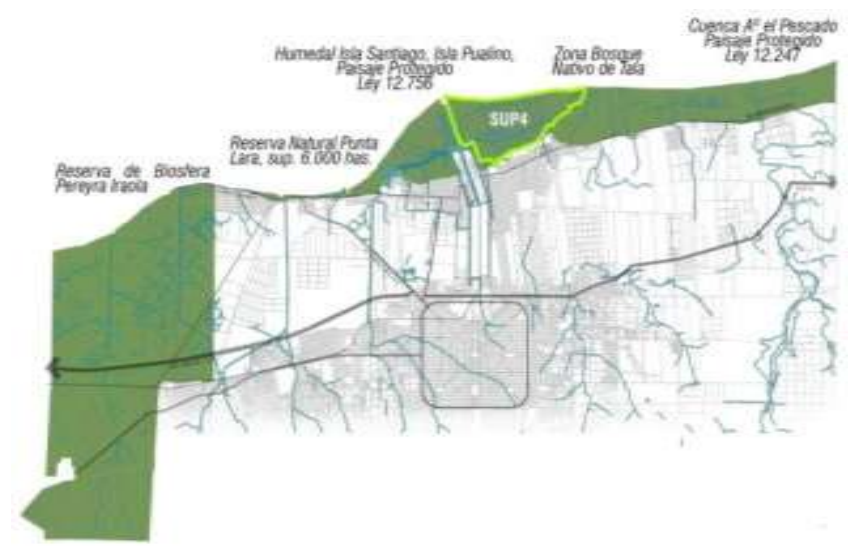

Corredor ecológico.

Elaboración propia.

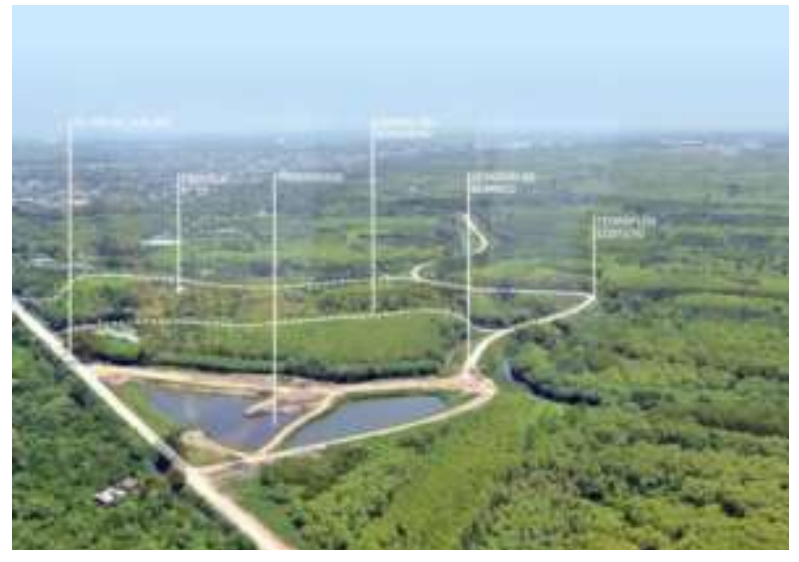

Vista aérea del recorte del área de estudio.

Elaboración propia en base a imágenes tomadas de google earth. Autor desconocido.

A los efectos de identificar claves para el proyecto, se articulan los aportes teóricos de la etnobotánica: Para conservar la biodiversidad es necesario entender cómo las culturas interactúan con sus paisajes a lo largo del tiempo. La etnobotánica es una disciplina cuyo objetivo consiste en analizar la interrelación entre sociedades humanas y comunidades vegetales en su contexto ambiental y sociocultural. Por ende, desde el enfoque etnobotánico, el concepto de paisaje adquiere una dimensión de fenómeno cultural, en donde los espacios físicos son escenarios dinámicos que reflejan una intrincada red de personas, lugares y recursos a lo largo del tiempo.

El proyecto busca la relación directa entre el productor y el consumidor, eliminando cadenas de intermediación, poniendo en valor la producción local, generando empleo, promoviendo la formalidad y el asociativismo. Busca potenciar el turismo de la zona, ya que está ubicado en un lugar estratégico en la costa del río, con la posibilidad de que los vecinos puedan ir a comprar desde la boca del productor los productos típicos locales.

El proyecto de paisaje hace hincapié en la relación del hombre con su entorno natural, reflejada en diversas actividades: caminatas, recorridos y juegos diversos que buscan generar una relación más 
amable con el espacio que se habita, a modo de promover una mejora en la manera que actualmente se vive ese espacio. Para ello, se proponen mediantes "circuitos etnobotánicos" actividades diversas que fortalezcan la relación hombre-naturaleza: circuitos de observación de flora y fauna, producción de frutales y hortalizas a partir de cultivos hidropónicos, conservación de flora nativa, charlas informativas, elaboración de productos artesanales (vino, miel, artesanías con junco), actividades educativas, ganadería, juegos para niños, etc. El uso del agua en algunas actividades como elemento esencial y la interacción constante con la vegetación, apuntan a generar una relación más amable con la naturaleza del lugar. Fomentando el desarrollo local, el interés de visitar el lugar (turistas y habitantes de la zona) y dando la posibilidad de acceder a un parque público con una función vital en dos ciudades que padecen la escasez de espacios verdes recreativos.

\section{CIRCUITOS ETNOBOTÁNICOS PROPUESTOS.}

\section{Parrales históricos:}

A fines del siglo XXI la uva "isabella" tuvo lugar históricamente con la llegada masiva de inmigrantes al Puerto de Berisso, donde en las tierras bajas de la isla y del monte costero, se cultivaban traída por inmigrantes italianos que conocían bien su aroma frutado y su particular sabor, para la producción del conocido "vino de la costa". Se propone la actividad "parrales históricos", pensada para cualquier época del año, teniendo épocas de recolección, elaboración, propagación de plantas y charlas culturales informativas. El objetivo de este recorrido es seguir difundiendo a través de actividades recreativas la cultura que caracteriza la producción de vino de la costa.

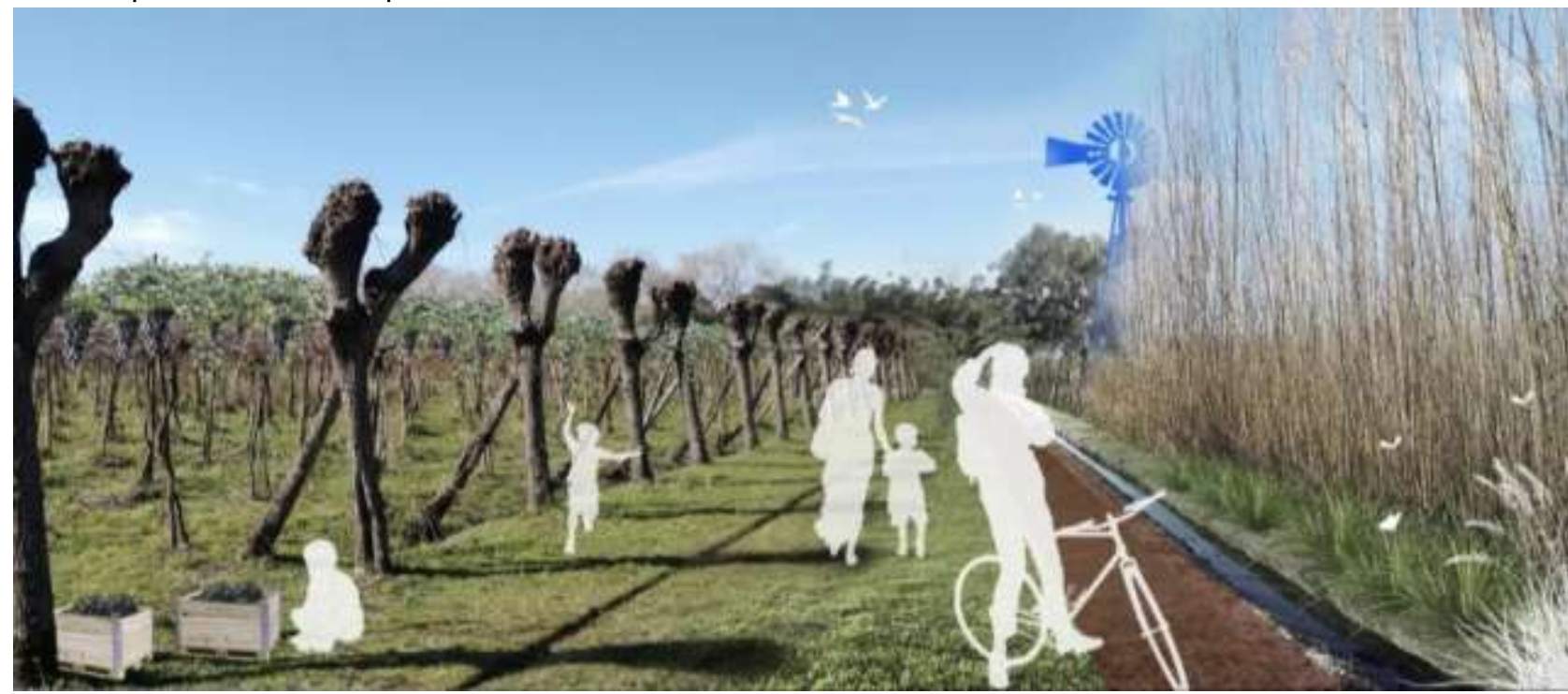

Circuitos parrales históricos.

Elaboración propia en base a fotografías tomadas en el área de estudio.

\section{- Hidroponía comunitaria:}

Es un método innovador, eficiente y sustentable de producir alimentos en ámbitos urbanos, una técnica utilizada para cultivar plantas usando soluciones minerales para no realizar la totalidad de la producción local en suelo. El proyecto propone el desarrollo de huertas hidropónicas en la escuela primaria №15 de Berisso (instalada en el área de proyecto), con el objetivo de promover la implementación de la huerta como recurso didáctico para la enseñanza y la investigación, incentivando la sensibilidad e interés por los problemas ambientales y contribuyendo a desarrollar los valores, aptitudes y conocimientos. 


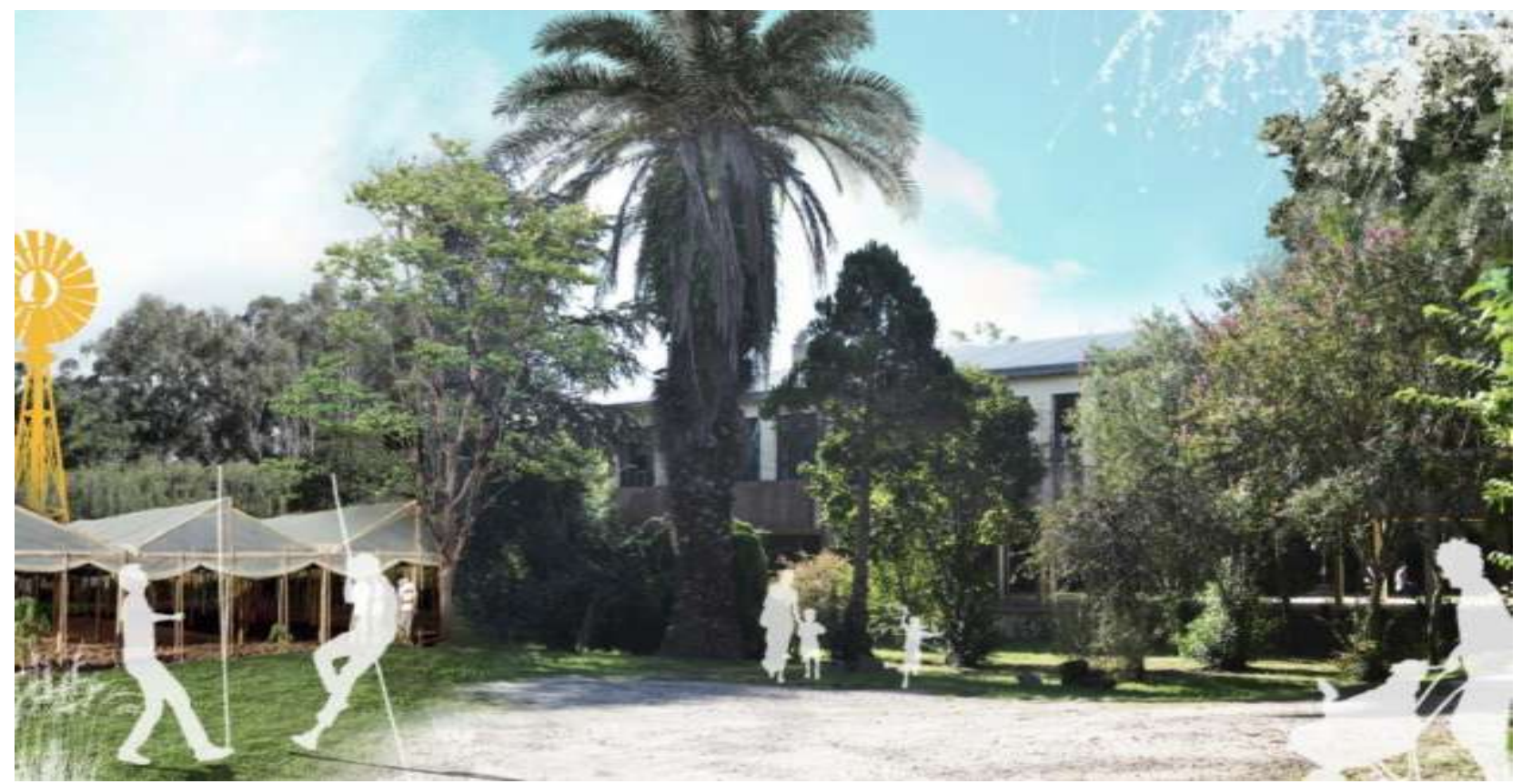

Huertas hidropónicas en la escuela primaria №15 de Berisso.

Elaboración propia en base a fotografías tomadas en el área de estudio.

\section{Cañas laberínticas:}

Las plantas de cañas son especies introducidas y naturalizadas en el ambiente rioplatense. Crecen de manera espontánea generando tramas densas de vegetación. Se proponen juegos interactivos y recreativos para todas las edades sobre todo para los niños, apuntando a nuevos campos de exploración. El recorrido "cañas laberínticas" guarda la idea del descubrimiento, de perderse en lo verde, de no saber lo que hay delante, despertando los sentidos sensoriales. Se proponen laberintos con cortes de las cañas en diversas alturas: de crecimiento natural, cañas cortadas a $1.50 \mathrm{mts}$ y otras más bajas para los más pequeños con altura no mayor a los $0.90 \mathrm{~cm}$. La dinámica sinuosa del recorrido también está sujeto a las edades, siendo breves los recorridos para los más chicos. El mantenimiento del circuito a modo de actividades también fomenta el control de la planta para evitar que se siga propagando, dando espacio al desarrollo de las plantas nativas.

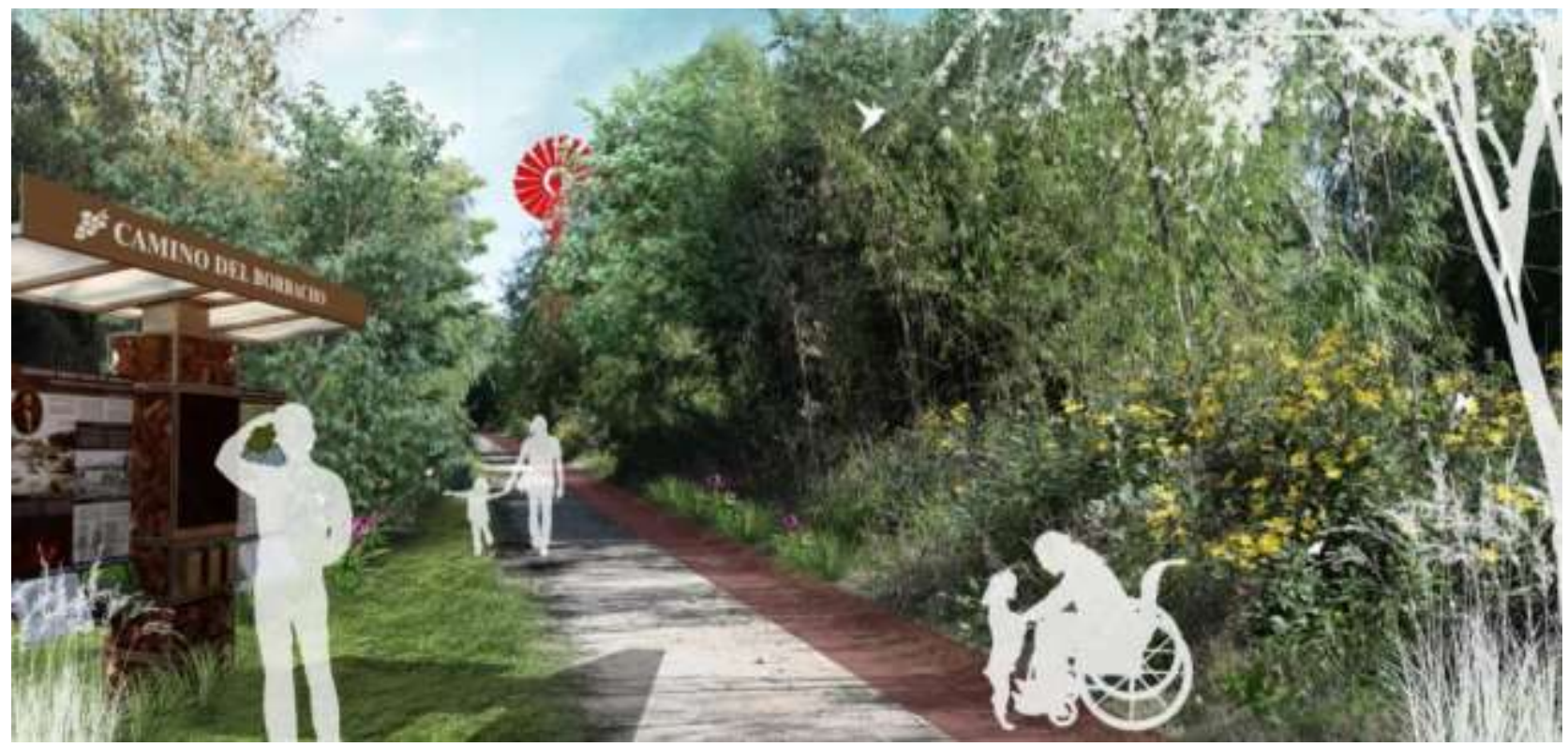

Circuito cañas laberínticas.

Elaboración propia en base a fotografías tomadas en el área de estudio. 


\section{- Tanques australianos y molinos}

Los molinos y tanques australianos son típicos en paisajes rurales y por lo general actúan en conjunto: el molino bombea el agua de las napas por medio de un pistón y trabaja con la fuerza del viento (bombeo eólico) juntando agua para llenar los tanques que, por lo general son bebederos para el ganado. Si bien hay varios diseños y tipos, suelen ser utilizados a pequeña escala, para abastecer de agua potable a comunidades rurales, 0 en pequeños sistemas de riego. El proyecto incorpora técnicas históricas asociadas a la producción ya que son consideradas apropiadas para fomentar el desarrollo local junto con el turismo, de una manera más amigable con el entorno. Se valora la labor del molino como provisión de agua para el riego, y también la superficie del tanque para los almácigos de cultivos hidropónicos en épocas de siembra adecuadas para cada hortaliza. El mismo, contará también con vegetación que sea capaz de absorber con sus raíces metales contaminantes (característica actual del agua del Rio de La Plata).

\section{Corredores frutales}

El ñangapiry, pittanga o árbol grosellero es un arbusto árbol nativo de matorrales ribereños. Su fruto es dulce comestible. Es una especie muy empleada en la medicina. Raramente en las ciudades o viveros se vea esta especie ya que está muy poco difundida. Se proponen recorridos de reconocimiento de flora nativa, donde también de septiembre a enero puedan recolectarse sus frutos y degustarlos. También podrán elaborarse dulces de pittanga. Los árboles estarán dispuestos en forma de caminos sinuosos, en asociación con flora aves y mariposas nativas para avistaje.

\section{Apicultura}

En la actualidad Berisso cuenta con aproximadamente 20 apicultores que producen unos $24.000 \mathrm{kgs}$ de miel por temporada, en un predio exclusivo para la Asociación de Productores Apícolas de Berisso (APABE) ubicado en Los Talas, otorgado por la Municipalidad de Berisso en el año 2013/2014. El Parque Etnobotánico propone una extensión de la actividad apícola que permita seguir beneficiando a la producción regional y el desarrollo local, y también como circuito de interés turístico. En este sector se podrá aprender de la actividad apícola y participar de la recolección de las colmenas en invierno. Se proponen talleres de capacitación para aquellos interesados en el rubro y recorridos de vegetación melífera (atractora de abejas) los cuales expliquen el ciclo y su función esencial en la producción de la miel.

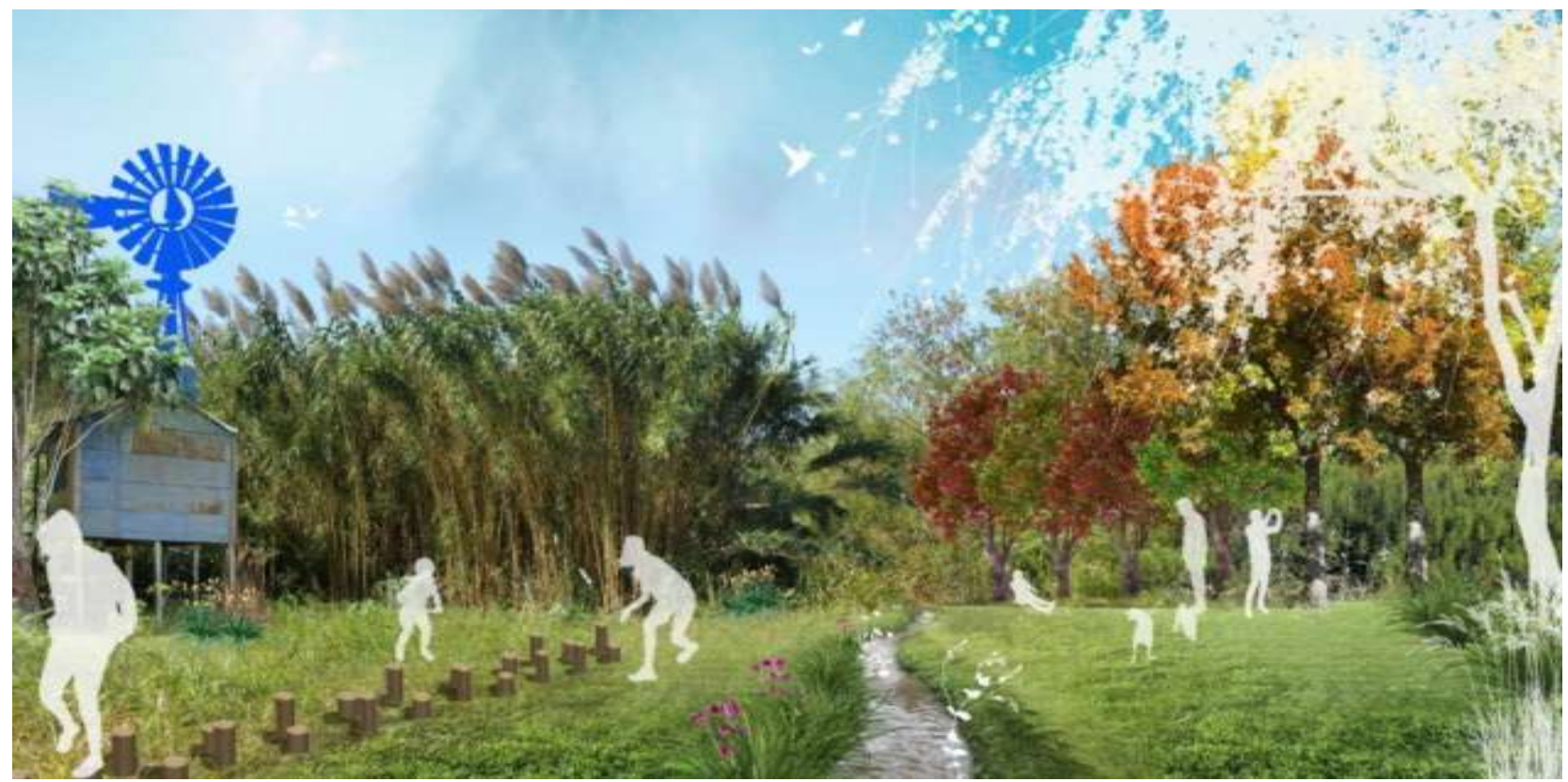

Circuitos en interacción.

Elaboración propia en base a fotografías tomadas en el área de estudio. 


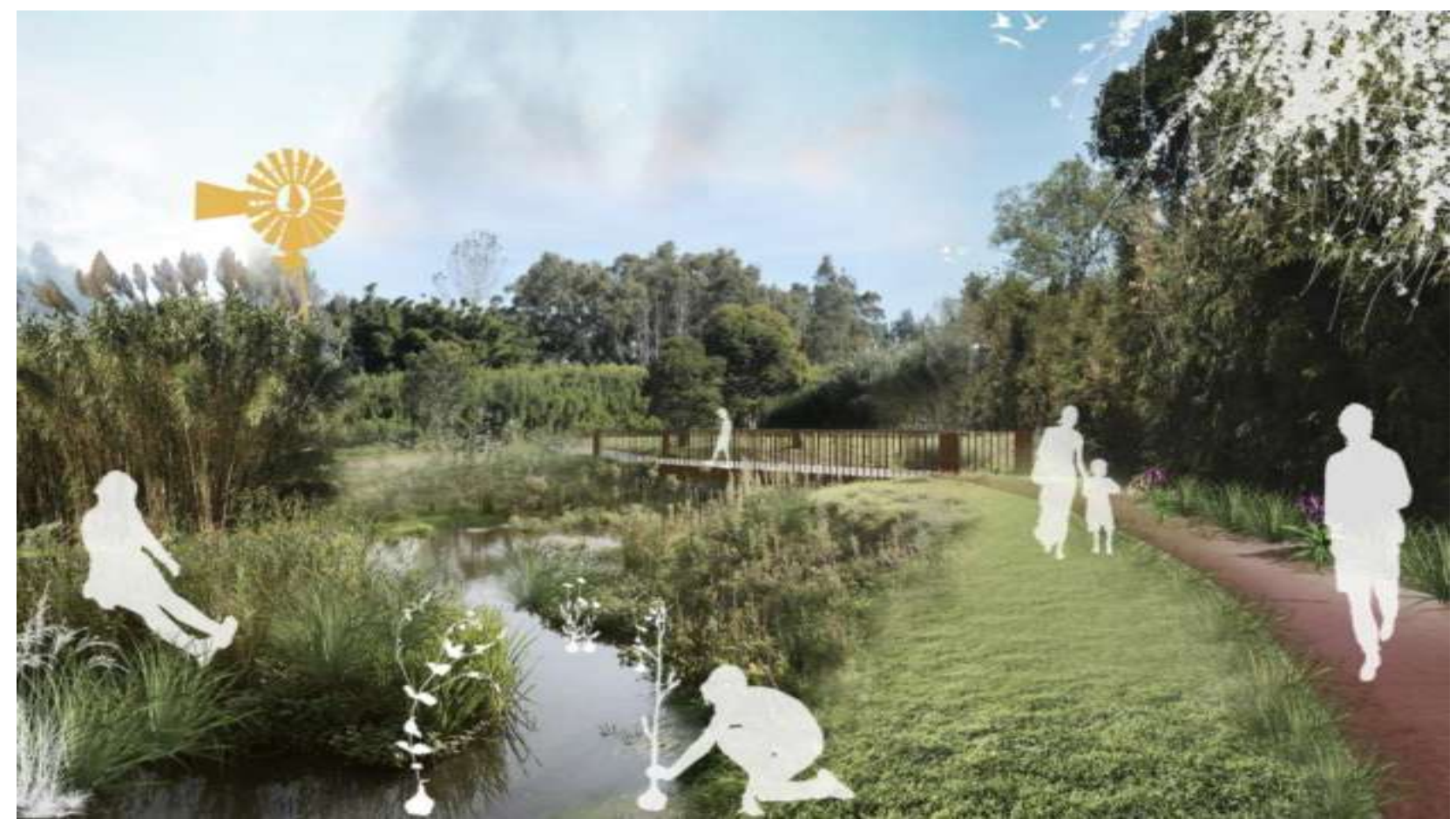

Circuitos en interacción.

Elaboración propia en base a fotografías tomadas en el área de estudio.

\section{CONCLUSIONES}

El trabajo se constituye como una herramienta de gestión del territorio que permite transformar la relación entre la producción local viñatera y turismo asociado a esta actividad, en pos de mejorar la calidad de vida de la población, el ambiente natural y antropizado, no sólo para las islas Santiago y Paulino, sino como propuesta para todo la región costera del Gran La Plata.

De esta forma, se espera haber contribuido a repensar la región de manera integral, recurriendo al concepto de paisaje como articulador entre los diferentes condicionantes del proceso, logrando un resultado superador de la situación actual, a través de un trabajo interdisciplinar, a partir de la mirada del arquitecto como del paisajista.

\section{REFERENCIAS}

- ÁBALOS, I. (2005); Atlas Pintoresco Vol. 1: el observatorio. Barcelona: Gustavo Gili.

- BAPTISTA, G. (2013); Laboratorio internacional de paisajes culturales. Montevideo: Empresa gráfica mosca.

- BERQUE, A. (2009); El pensamiento paisajero, Biblioteca Nueva Madrid.

- BESSE, J. M. (2006); Las cinco puertas del paisaje. En J. Maderuelo (dir.), Paisaje y pensamiento. (pp. 145-171). Madrid: Abada Editores, S.L.

- CAVENARI, P. et al. (1998); Los humedales de la Argentina: clasificación, situación actual, conservación y legislación., en el trabajo de Martínez, Omar Raúl; Hurtado, Martín Adolfo y Giménez, Jorge Eloy. "Caracterización ambiental de los humedales costeros del Río de La Plata". Provincia de Buenos Aires, Argentina. En Revista UnG, Geociências. Wetlands Internacional. 
- $\quad$ CONSEJO DE EUROPA (2000). Convenio Europeo del Paisaje. Florencia. Italia.

- FONT, J. N. (1989) “Paisaje y turismo”. Estudios Turísticos 103: 35-45

- LERNER, J. (2009); Acupuntura Urbana. Ed. Record. Rio de Janeiro. Sao Paulo.

- MÁRQUEZ, F. (2011); Planificación diseño y gestión participativa del paisaje. Editorial Nobuko

- MATA, R.; GOMEZ J.; y FERNANDEZ S.; (2001) “El paisaje, calidad de vida y territorio" Págs. 27 40. Revista Analisis Local. № 37. Julio- Agosto.

- $\quad$ MICHELLOD, OE. (2001); Paisaje: reflexiones. Ed. Al Margen, Berisso, Argentina.

- $\quad$ ROGER, A. (2007); Breve tratado del paisaje. Madrid: Editorial Nueva, S.L.

- SABATÉ J. (2008); Proyectar el territorio en tiempos de incertidumbre, Ed. UPC, Barcelona.

- SANTINELLI, G (2015); Gestión del proyecto de paisaje costero ribereño del partido de Quilmes. Lineamientos generales - plan maestro. Municipio de QUILMES. Unidad Ejecutora del Proyecto de la Ribera.

- SANTOS, M (2000). “La naturaleza de espacio”. España. Editorial Ariel.

- SILVESTRI, G., \& ALIATA, F. (2001). El paisaje como cifra de armonía. Buenos

- VARELA, L. (2001). Paisaje, reflexiones. La Plata, Buenos Aires: Al Margen, Colección Universitaria, Arquitectura, $1^{\circ}$ Edición. 